\title{
Muntlig historia i grundutbildningen
}

\section{Av Lars Berggren \& Mats Greiff}

- Malmö högskola och staden

- Grundutbildning i historia vid Malmö högskola

- Erfarenheter från arbetet tillsammans med studenterna

- Projekt

- Muntlig historia och underordnade gruppers emancipation

- Att skapa historiemedvetande - eller att ha beredskap för framtiden

- $\underline{\text { Referenser }}$

\section{Malmö högskola och staden}

Fram till 1998 var Malmö den enda av de tre storstäderna i Sverige som inte hade någon egen högskola. Människor som ville bedriva högskolestudier var hänvisade till det närbelägna och traditionstyngda universitetet i Lund eller någon annan högskoleort $\mathrm{i}$ landet. Detta strukturella förhållande kunde säkerligen verka avskräckande för vissa grupper i vilka den akademiska traditionen var svag. Malmö präglades i hög grad av en befolkning med sina rötter i en industriarbetarklass. Andelen invandrare var också hög. När Malmö högskola etablerades sommaren 1998 fanns redan ett övergripande mål formulerat. Högskolan skulle arbeta för att rekrytera studenter från miljöer där man av tradition inte sökte sig till högre studier, dvs i första hand arbetarklass och människor med invandrarbakgrund. I målen för högskolan betonades också att den skulle ha relevans för regionen och dess utveckling.[1] En avgörande faktor bakom etablerandet av högskolan var att Malmö under 1980- och 90-talen genomgick svårartade kriser av såväl ekonomisk som social karaktär.

Den deindustrialisering som skedde i stora delar av Västeuropa under 1900-talets senare decennier drabbade Malmö med kraft. Under 1960- och 70-talen kompenserades detta av en stark expansion av den offentliga sektorn. Men när den kommunala ekonomin försvagades under slutet av 1980- och hela 90-talet steg arbetslösheten kraftigt. Högskolan, liksom bron till Köpenhamn, sågs som en väg in i den nya ekonomi som skulle skapa välstånd i regionen.

Samtidigt som deindustrialiseringen fortgick och den kommunala ekonomin försvagades skedde en icke obetydlig flyktinginvandring. En omfattande immigration från södra Europa hade skett redan under 1950- och 60-talen, då industriföretagen hade ett stort behov av importerad arbetskraft.[2] Den nya immigrationen under 1980- och 90-talen hade en annan karaktär. Flyktingar från främst asiatiska och afrikanska länder kom till Sverige. Eftersom deindustrialiseringen pågick blev det allt svårare för de nya invandrarna att finna en plats på arbetsmarknaden. Därmed försvårades också integrationen i samhället. Den gamla klassbaserade boendesegregation som karakteriserat Malmö fick ytterligare en dimension, den etniska. Trots de tecken på ekonomisk återhämtning med etablerandet av nya tjänsteoch kommunikationsföretag och förbättringar av infrastrukturen med bl a Öresundsbron lever fortfarande många Malmöbor på socialbidrag och arbetslöshetsunderstöd. En förhållandevis stor del av de senaste decenniernas invandrare lever under sådana förhållanden. Detta visar att det finns en etniskt grundad marginalisering.[3]

Högskolan är till sin uppbyggnad tvärvetenskaplig och innefattar medicinska, tekniska, naturvetenskapliga och humanistiskt-samhällsvetenskapliga perspektiv. Utvecklingen i 
Malmö, tillsammans med målen för högskolan, innebar en utmaning när historieämnet och dess innehåll skulle konstrueras. Hur skulle vi skapa ett historieämne som skulle kunna tilltala och vara till nytta för människor med arbetarklass- och invandrarbakgrund? Hur skulle vi skapa ett historieämne med betydelse för regionen och dess invånare? Med vår långa bakgrund som socialhistoriker och erfarenheter av muntlig historia - inte bara som en metod utan också som ett demokratiskt perspektiv på ämnet - insåg vi möjligheterna att göra en sådan inriktning på historia som profil på ämnet. Genom att använda muntliga källor kan man nå människor, bl a arbetare, arbetarklasskvinnor och invandrare, som ofta inte har fått uttrycka sina erfarenheter i ett traditionellt skriftligt källmaterial. Detta har på följande sätt formulerats av Gary Y Okihiro:

Oral history is not only a tool or method for recovering history; it also is a theory of history which maintains that common folk and the dispossessed have a history and that this history must be written.[4]

En av den muntliga historiens förgrundsgestalter engelskmannen Paul Thompson har betonat att muntlig historia i sig själv har demokratiska och sociala funktioner.[5] Som många muntliga historiker har framhållit finns det starka kopplingar mellan muntlig historia och historia underifrån. Därför kräver arbete med muntlig historia ett intensivt samarbete mellan akademiska historiker och vanliga människor, som har varit aktörer på 1900-talets historiska arena. Därför är muntlig historia ett perspektiv som faller väl in i Malmö högskolas intentioner. Det kan sannolikt också fylla en viktig funktion för skapandet av identitet och självförståelse bland Malmös arbetare och immigranter. Därigenom skapas institutionella förutsättningar för ett dialektiskt samspel mellan historieforskning och historieundervisning vid högskolan och vanliga människors erfarenheter. Genom medverkan i studier eller projekt i muntlig historia kan människor tillägna sig djupare insikter om sin egen roll i historiska förändringsprocesser. På så sätt blir det möjligt för dem att inse att de faktiskt har en roll i skapandet av historia. Denna emancipatoriska dimension kan skapa en drivkraft för såväl studenter som andra människor att förändra sina livsvillkor.[6]

Det dialektiska samspelet innebär självklart att historiker också kan lära sig av de människor som berättar om sina erfarenheter. De utgör inte bara källor utan kan också bidra med perspektiv och tolkningar, vilka i sin tur bearbetas av historikern.

Because oral history is predicated on an active human relationship between historians and their sources, it can transform the practice of history in other ways. Recorded oral testimony is not just an historical source to be mined for information and subjected to historical interpretation by the interviewer and other historians. In an interview the narrator not only recalls the past; they also offer an interpretation of that past. In effect, oral history can challenge the special status of the historian and democratize the practice of history.[7]

Det handlar emellertid inte bara om att människor ute i samhället ska engageras i olika muntliga historieprojekt, utan också i hög grad om att knyta mera långsiktiga kontakter mellan dem och högskolan. Genom sådana kontakter kan också högskolestudier avdramatiseras, och på så sätt kan människor från icke-studievana miljöer medvetandegöra sig om att studier också är möjliga för dem.

\section{Grundutbildning i historia vid Malmö högskola}

Vid Malmö högskola finns två inriktningar på historieämnet, Historia med kulturanalys och Europastudier med historisk inriktning. Vi kommer här att uppehålla oss vid det förstnämnda. Denna inriktning finns upp t o m 80 poäng. Under första terminen ges bl a en kronologisk översiktskurs innehållande i första hand socialhistoriska och kulturanalytiska perspektiv. Eric Hobsbawms samhällshistoriska ansats[8] och underifrånperspektiv har varit utgångspunkter för kursernas uppläggning. Innehållet genomsyras av perspektiven klass, genus och etnicitet. Första terminen avslutas med en kurs i muntlig historia. I denna 
ligger fokus på metodfrågor, men också på en diskussion om muntlig historia som perspektiv och ideologi. Studenterna genomför självständiga projektarbeten i vilka de får en första vetenskaplig träning i att genomföra intervjuer och tolka sina resultat.

Under andra terminens metodkurs utvecklas diskussionen om bruket av muntliga källor. I kursen finns också en djupare problematisering av frågor om källornas värde och tolkningsbarhet. Detta görs i ett sammanhang där också bruket av olika slags skriftliga källor problematiseras. I tematiska fördjupningskurser kommer studenterna i kontakt med forskning, som bygger på muntliga källor. Utifrån dessa studier blir det möjligt för studenterna att utveckla projekt, vars resultat presenteras i B-uppsatsen. Studenterna kan också samarbeta i projektgrupper med olika infallsvinklar, t ex underifrånperspektiv på Malmös 1900-talshistoria.

De tredje och fjärde terminerna är snarlika de flesta andra historieutbildningar, med en hög grad av valbarhet vad gäller inriktningar och perspektiv. Förhoppningsvis har studenterna blivit så inspirerade av att arbeta med muntlig historia att de fortsätter med denna ansats i sina C- och D-uppsatser.

De studenter som har valt att läsa, det i den nya lärarutbildningen ingående, huvudämnet Historievetenskap och lärande kommer också i kontakt med muntlig historia. Första terminens huvudämnesstudier inleds med kursen "Våra svenska 1900-tal". I denna skriver studenterna en biografi som bygger på en intervju med någon äldre släkting. På så sätt knyter man samman den lilla historien underifrån med den stora. Studenterna medvetandegörs också om de många skilda perspektiv som finns på 1900-talets historia.

Dessa lärarstudenter kommer, liksom en del av de andra historiestudenterna, i framtiden att arbeta som lärare för olika åldersgrupper. Förhoppningsvis har de blivit så inspirerade av den muntliga historien att de kan arbeta med sådana perspektiv bland sina elever. På så sätt kan uppfattningen om vad historia är förändras bland barn och unga och nya studieområden kan introduceras i skolan.[9]

\section{Erfarenheter från arbetet tillsammans med studenterna}

Den första terminens muntliga historiekurs inleds med en diskussion om vad muntlig historia är. Därvidlag diskuteras teoretiska och metodiska aspekter på muntlig historia, liksom perspektivfrågor. Därefter bearbetas konkreta metodiska frågor som hur man genomför en intervju, hur man tolkar intervjuer samt källkritiska frågor. De muntliga källornas dubbla karaktär av att vara såväl kvarlevor som berättelser diskuteras och problematiseras. Detta innebär att frågan om historia som såväl konstruktion som rekonstruktion bearbetas. Som kurslitteratur används bl a Paul Thompsons Det förgångnas röst och delar av The Oral History Reader.

Med blott fyra veckors arbete kan det tidsmässigt vara svårt att finna informanter. Därför rekommenderar vi studenterna att välja ett projektområde, som innebär att de kan finna informanter i sin egen omgivning. Det kan t ex röra sig om släktingar, grannar eller vänner.

Under tiden studenterna fältarbetar hålls regelbundna seminarier i vilka frågor kring konkreta tolkningar och metoder bearbetas. På så sätt blir det ett slags handledning som kommer alla studenterna till godo.

I studenternas uppsatser förväntas det att de har en metodisk diskussion som relaterar kurslitteraturen till de egna empiriska resultaten och tolkningarna. Kursen ligger emellertid på A-nivån, vilket innebär att många studenter inte har någon erfarenhet av vetenskapligt arbete. Därför är den teoretiska och metodiska nivån inte alltid så hög. Men de empiriska resultaten är däremot oftast intressanta. Det finns dock också uppsatser av hög kvalitet. Kursen fyller emellertid sin funktion och lägger en grund för vidare studier och ger inspiration att fortsätta med muntlig historia. 


\section{Projekt}

Studenternas projekt varierar starkt i inriktning. Bland dem som gjordes våren 2001 finns bl a:

- Från Serbien till Sverige på 1960-talet

- Hur var livet som ung på 1940-talets Limhamn

- Släkten Andersson/Rundkvist. En källkritisk granskning av ett historiskt material

- Ett arbetsamt liv. Om försörjning under förra seklet

- Att komma ut. Fyra lesbiska kvinnor ur två generationer

- Är du rädd? Vad är barn från olika tidsperioder rädda för?

- En fiskehistoria

- Skolan förr

- Oscar och samhället

- Kommunismen. Om livet i Polen

- Folksjukdomar under 1900-talet

- Barns lekar förr och nu. En jämförelse

- Kvinnorna i Söndraby

- Hur var det att leva i republiken Irland medan konflikten i Nordirland pågick. En ung människas perspektiv

- Bakom järnridån

- Byalaget, bystämmorna och spruthuset i Sätofta by

Flertalet studenter väljer teman som har anknytning till den egna bakgrunden och som har betydelse för den egna identiteten. Ett sådant tema handlar om erfarenheter av migration antingen från främmande länder eller från den svenska landsbygden. Andra väljer att behandla teman som har anknytning till äldre släktingar.

Projekten har fått många - för såväl forskare som studenterna själva - intressanta resultat. Ett exempel på detta är Katarina Ek, som har intervjuat två systrar och jämfört deras olika minnesbilder av modern. I uppsatsen beskriver Ek föredömligt hur vardagslivets strävan tedde sig för en kvinna född på landsbygden 1890. Sedermera gifte sig denna med en bonde och födde nio barn, varav sju överlevde barndomen. Vid 59 års ålder dog hon i cancer.[10] Metoden att analysera två systrars olika syn på modern ger en särskild metodisk styrka åt uppsatsen.

Susanna Johansson har skrivit en annan livshistoria. Den fokuserar på villkoren för unga kvinnor i läroverket kring 1930. Informanten Anna-Lisa minns hur det var att lämna realskolan:

De allra flesta av mina kamrater skulle ju sen ha ett jobb. Många av flickorna fick jobb på kontoren till postorderfirmorna, men man måste vara 16 år för att få jobb där. Jag var alltså för ung för det. I och med att flickor från och med läsåret 1928/29 fått tillträde till Borås Gossläroverk och att det samma år som jag tog realen hade öppnats en helt ny treårig realgymnasielinje, blev det möjligt för mig att få fortsätta skolan. Det kändes väldigt spännande. Jag var den första i vår familj som fick göra det, och pappa hade aldrig haft råd att skicka mig till Rudebeckska Gymnasiet för flickor i Göteborg med inackordering där, vilket var en möjlighet för de förmögnare familjerna.[11]

När Anna-Lisa började sina studier på Borås Gossläroverk såg hon emellertid inte ut som den typiske lärjungen varken med avseende på klass eller kön. Det var en tuff erfarenhet för en arbetarklassflicka att konfronteras med en maskulin medelklasskultur:

Vi var då två flickor som började på den treåriga reallinjen höstterminen 1929, Märta och jag. Vi hade alltid tidigare gått i samskola och var vana vid pojkar som kamrater. Men pojkarna var inte vana vid flickor i skolan, så de var väl lite vilsna i början. Vana var heller inte lärarna. Fysikadjunkten t ex kunde 
komma fram till oss under laborationerna och säga: - Skall vi se hur de här opraktiska madamerna har det nu då? Det var den attityden hos vissa, men de allra flesta var helt korrekta och en del var ju omtyckta av alla elever för att de var så trevliga.[12]

Efter tre år I läroverket tog Anna-Lisa sin studentexamen. Hon sammanfattar examensdagen:

Jag tog studenten i maj 1932, nästan 18 år gammal. Min faster från Lund var hos oss på besök och många av mina egna och familjens vänner kom hem på uppvaktning. En av grannarnas pojkar tog med sin trattgrammofon och vi spelade 'Es gibt nur einmal, es kommt nicht wieder'... och dansade till sent. Sen var det studentbal med lärarna på skolan. Jag minns särskilt vår fysiklärare som bad om ursäkt för att han varit spydig mot oss flickor i början av gymnasietiden. Han hade nu förstått att även flickor kunde räkna fysik.[13]

På så sätt visas att enskilda personer som kunde bryta genusmönster kunde få stor betydelse. Efter några års apotekspraktik utbildade sig Anna-Lisa till farmaceut.

Flera uppsatser behandlar erfarenheter av migration. En del av dessa går tillbaka till förhållanden i hemlandet, medan andra fokuserar den första tiden i Sverige. Bland de förstnämnda finns flera uppsatser om levnadsförhållanden i östra Europa. Agnes Marx har intervjuat en äldre släkting, Mona, som föddes I Ungern under andra världskriget. Mona växte upp med sin moder och tre syskon. Hennes far försvann under kriget.

Vi väntade på den dagen då han skulle komma tillbaka från kriget. När kriget tog slut, släppte de många av de krigsfångar som tillfångatogs under kriget och då återvände många män till byn. Vi fick aldrig riktigt något klart besked om att han dött i kriget, det var bara något som vi antog eftersom han aldrig kom hem... och ja, man väntade ju allt på honom... Till och med in på 50-talet fanns det de som återvände till byn, som hade varit krigsfångar i

Sovjetunionen. Men vår pappa kom aldrig hem. Vi väntade på dagen när han skulle återvända från kriget.[14]

Mona berättar om svårigheterna under sin barndom och speciellt om moderns kamp för att försörja barnen. Det var svåra omständigheter för en ensamstående moder som dessutom led av TBC. Livet hade emellertid också ljusa sidor. Mona minns från sin ungdomstid när hon brukade gå på lokala danstillställningar:

Och där satt de gamla kärringarna på bänkarna i salens hörn och skvallrade om vem som hade på sig vad, vem som dansade med vem, varför de inte hade bjudit upp den och den och vem som aldrig kommer att bli gift [skratt]. Ja, just det, sen fanns det ju bion också. Dessa två nöjesmöjligheter fanns det, alltså bion och dansen.

När jag senare arbetade i Budapest, då jag var cirka 15 år gammal, fanns det olika sorters fritidssysselsättningar. Det vanligaste var att man dansade folkdans och vid vissa tillfällen t ex vid högtider så hade de olika dans- och sångshower, jag och min umgängeskrets gick ibland på utflykter till andra städer och ut i naturen. Resa utomlands kunde man ju inte göra, inte på den tiden. Men för det mesta så arbetade vi faktiskt.[15]

Enligt Mona trodde många människor att kommunismen skulle medföra bättre levnadsvillkor för folket. Mona ger emellertid flera exempel på hur den politiska friheten inskränktes under kommunisttiden. Hon pekar också på svårigheterna att resa fritt. Så var det särskilt efter den s k revolten 1956.

Mona sammanfattar sin nyanserade syn på kommunisttidens Ungern: 
Bättre var det inte. Man tycker aldrig om den typen av instängdhet och att staten alltid skall blanda sig i och kontrollera allting man gör och säger. Det måste finnas en viss frihet så att man inte känner att någon kontrollerar varje steg man tar. Vissa saker var faktiskt bra om man ser på samhället som helhet. Till exempel det att man alltid hade arbete och att om man arbetade så kunde man mer eller mindre leva på det man tjänade. Men just bara leva på det, det räckte knappt till något annat. Om man ville bygga eller köpa ett hus, krävdes det väldigt mycket pengar som man var tvungen att tjäna ihop, och det räckte oftast inte med bara en lön.[16]

Att många studenter väljer projektinriktningar med stor relevans för självförståelse innebär också att projekten har relevans för stadens invånare och identitetsskapande processer. Mot bakgrund av den rådande sociala och ekonomiska strukturen i Malmö är det därför inte heller svårt att identifiera viktiga och intressanta forskningsområden som kan bearbetas med hjälp av muntlig historia. Detta eftersom studier av samtida och pågående förändringar i levnadsvillkor och kulturskapande kräver ett historiskt perspektiv.

\section{Muntlig historia och underordnade gruppers emancipation}

Ett resultat av bruket av muntlig historia är att de människor man samarbetar med kan skapa sig en medvetenhet om sin egen roll i historiska förändringsprocesser. På så sätt bidrar muntlig historia inte bara till att den professionelle historikern får ökad kunskap utan den fyller också en emancipatorisk funktion för t ex marginaliserade och underordnade grupper I samhället.

En sådan grupp består av invandrare med olika ursprung. Efter 1945 rekryterades arbetare från södra Europa till industriföretag som hade svårt att skaffa inhemsk arbetskraft. År 1946 rekryterade Kockums manliga yrkesarbetare från norra Italien. Senare omfattade rekryteringen också arbetare från bl a Tyskland, Jugoslavien och Portugal. Hustrur och kvinnliga släktingar till dessa arbetare kunde med lätthet finna arbete i de stora textilföretagen eller i livsmedelsindustrin. Hur upplevde de invandrade arbetarna sin tillvaro i Sverige? Vad övertygade dem om att flytta och i vilken mån uppnåddes deras förväntningar? Vilka svårigheter upplevde de på arbetsplatserna och i resten av det svenska samhället? Sådana frågor är av största vikt för identitetsskapandet hos deras barn och barnbarn; människor som i dag kan uppleva identitetsproblem. Mera nyanlända invandrargrupper synes ha haft större svårigheter att etablera sig själva i samhället än de som kom under 1950- och 60-talen. De nya grupperna består huvudsakligen av flyktingar från Asien och Afrika med många olika kulturella bakgrunder. Eftersom de inte har blivit direkt rekryterade som arbetare och deras kulturella och sociala kapital inte uppskattats har de haft stora svårigheter att bli attraktiva på arbetsmarknaden. Även dessa människor har upplevt identitetsproblem. Många har framhållit att de varken betraktar sig som svenskar eller t ex somalier. Många har också svårt att se någon framtid i något av länderna. Till detta skall läggas att det är viktigt att beakta de skillnader som finns t ex i synen på könsrelationer mellan vissa invandrargrupper och den gängse svenska diskursen. Många flickor och unga kvinnor med invandrarbakgrund uppfattar svenska kvinnors frihet som relativt stor och försöker uppnå en liknande ställning. Detta kan leda till svåra spänningar inom invandrarfamiljer eftersom emancipatoriska strävanden kolliderar med äldre patriarkala värdesystem.

En annan grupp består av alla de kvinnliga arbetare som en gång sålde sin arbetskraft till textil- eller livsmedelsindustrin. Hur upplevde de sitt arbete? Vad gjorde de egentligen när de arbetade? På vilket sätt innebar arbetsdelningen också en könsarbetsdelning? Hur tedde sig relationerna mellan män och kvinnor i fackföreningsrörelsen? Vilka är erfarenheterna från fabriksnedläggningarna på 1960-talet? Mellan detta decennium och 1980-talet byggdes den offentliga sektorn ut. Detta innebar att anställningsmöjligheter inom hälsooch sjukvård, utbildning, socialvård m m ökade kraftigt. En stor del av de anställda inom den offentliga sektorn utgörs av kvinnor. Hur var arbetsförhållandena här? Vilka 
arbetsuppgifter hade kvinnorna? Upprätthölls könsarbetsdelningen här också? Skilde sig förutsättningar för det fackliga arbetet mellan privat och offentlig verksamhet? Hur organiserades hemarbetet i familjer där både man och hustru hade förvärvsarbete på heltid?

Genom kontakter med akademiska forskare och studenter kan människor som inte betraktat sig som historiskt betydelsefulla stimuleras att reflektera över sina egna roller i historien och samtidigt medvetandegöras om dem. Detta gäller särskilt för grupper av människor som inte har någon tradition av att bedriva akademiska studier med historiska perspektiv. Men genom muntlig historia ur ett underifrånperspektiv synliggörs att alla på olika sätt deltar i och bidrar till samhälleliga förändringsprocesser. På så sätt kan människor också skaffa sig verktyg för att förändra sin livssituation och villkoren för de kollektiv de tillhör. Det är en viktig uppgift för Malmö högskola att befrämja detta.

\section{Att skapa historiemedvetande - eller att ha beredskap för framtiden}

Fördelen med att målmedvetet tillämpa muntlig historia i grundutbildningen, såväl den reguljära som historielärarutbildningen, är att studenterna inte bara uppnår färdighet $\mathrm{i}$ att använda muntlig metod, utan också att de precis som informanterna medvetandegörs om sin roll som historiens aktörer. Härigenom bidrar kurserna inte endast till ökad kunskap men också till att utveckla studenternas historiemedvetande. Många av dem har inte tidigare reflekterat över på vilket sätt människor ur alla sociala grupper är aktiva i skapandet av historia. Exemplet med Anna-Lisa som refereras ovan visar hur en vanlig arbetarklassflicka kunde bryta köns- och klassbarriärer och på så sätt bidra till utvecklingen av ökad jämställdhet i svensk utbildning. I studenternas uppsatser finns det talrika exempel på jämförbara fenomen.

I de flesta fall finner studenterna det både intressant och spännande att arbeta med muntlig historia. Många av dem har i utvärderingar framhållit betydelsen av att arbeta med mikrohistoria och därigenom med andra perspektiv än de som betraktar samhällets eliter och internationella konflikter. Ett flertal studenter har betonat den betydelse själva intervjuarbetet har haft både för deras eget självmedvetande och för historiemedvetandet.

Bland annat den danske historikern Bernhard Eric Jensen har framhållit att begreppet historiemedvetande berör människors grundläggande syn på livet och samhället.

One may speak of historical consciousness, when people link their interpretations of the past not only to their understanding of the present but also to the forming of their expectations with regard to the future.[17]

Därigenom blir förbindelsen mellan det förflutna, nutiden och framtiden central. Den amerikanske historikern Harvey J Kaye ser historiemedvetande som "an appreciation of the making of history, an awareness of the `effort and sacrifice which the present has cost the past and which the future is costing the present"'.[18] Genom att förstå andra människor i en samhällelig kontext blir det möjligt för en människa att öka sin självförståelse. På så sätt bidrar muntlig historia inte bara med en emancipatorisk dimension till historiestudiet utan också med en existentiell.

(C) Lars Berggren \& Mats Greiff

\section{Referenser}

Berggren, Lars \& Greiff, Mats, "The Malmö Region in Southern Sweden", i Schulze, Rainer (red) Industrial Regions in Transformation, Essen 1993.

Berggren, Lars \& Greiff, Mats, Från sillamarknad till SAAB-fabrik, Ystad 1992.

Ek, Katarina, Britta och Stina minns sin mor, opublicerad uppsats Malmö högskola, januari 2001.

Greiff, Mats, "Arbetarhistoriska forskningscirklar", i Industrialismens kulturarv. Rapport 
fra Farums Arkiver \& Museer, Farum 2000.

Hobsbawm, Eric J. "From Social History to the History of Society", i Daedalus, 100, 1971. Högskola i Malmö, SOU 1996:36.

Jensen, Bernard Eric, "History and the Politics of Identity: Reflections on a Contested and Intricate Issue", i Ahonen, Sirkka et al (red), Historiedidaktikk i Norden 7, Trondheim 1999.

Johansson, Susanna, Ung kvinna, gymnasist och student i 1930-talets Sverige, opublicerad uppsats Malmö högskola, januari 2001.

Kaye, Harvey J, "Why Do Ruling Classes Fear History?" and Other Questions, New York 1997.

Marx, Agnes, Bakom järnridån, opublicerad uppsats Malmö högskola, juni 2001.

Okihiro, Gary Y, "Oral History and the Writing of Ethnic History", i Dunaway, David K \& Baum, Willa K (eds) Oral History. An Interdisciplinary Anthology, Walnut Creek 1996.

Ross, Alistair, "Children Becoming Historians. An Oral History Project in a Primary

School", i Perks, Robert \& Thomson, Alistair (eds) The Oral History Reader, London 1998.

Stigendal, Mikael, Sociala värden i olika sociala världar, Lund 1999.

Thompson, Paul, "The Voice of the Past: Oral History", i Perks, Robert \& Thomson, Alistair (eds), The Oral History Reader, London 1998.

Thomson, Alistair, "Unreliable Memories? The Use and Abuse of Oral History", i Lamont, William (ed.), Historical Controversies and Historians, London 1998.

[1] Högskola i Malmö, SOU 1996:36.

[2] Lars Berggren \& Mats Greiff, "The Malmö Region in Southern Sweden", i Schulze, Rainer (red) Industrial Regions in Transformation, Essen 1993.

[3] Lars Berggren \& Mats Greiff, Från sillamarknad till SAAB-fabrik, Ystad 1992, s 51ff; Mikael Stigendal, Sociala värden i olika sociala världar, Lund 1999.

[4] Gary Y, Okihiro, "Oral History and the Writing of Ethnic History", i Dunaway, David K \& Baum, Willa K (eds) Oral History. An Interdisciplinary Anthology, Walnut Creek 1996, s 209.

[5] Paul Thompson, "The Voice of the Past: Oral History", i Robert Perks \& Alistair Thomson (eds), The Oral History Reader, London 1998, s $21 \mathrm{ff.}$

[6] Mats Greiff, "Arbetarhistoriska forskningscirklar", i Industrialismens kulturarv. Rapport fra Farums Arkiver \& Museer, Farum 2000, s 38.

[7] Alistair Thomson, "Unreliable Memories? The Use and Abuse of Oral History", i Lamont, William (eds), Historical Controversies and Historians, London 1998, s 25.

[8] Eric J. Hobsbawn, "From Social History to the History of Society", i Daedalus, 100, 1971.

[9] Alistair Ross pekar på fruktbarheten med att använda muntlig historia i skolan i Alistair Ross, "Children Becoming Historians. An Oral History Project in a Primary School", i Robert Perks \& Alistair Thomson, (eds), The Oral History Reader, London 1998.

[10] Katarina Ek, Britta och Stina minns sin mor, opublicerad uppsats Malmö högskola, januari 2001.

[11] Susanna Johansson, Ung kvinna, gymnasist och student i 1930-talets Sverige, opublicerad uppsats Malmö högskola, januari 2001, s 3.

[12] Susanna Johansson, s 3.

[13] Susanna Johansson, s 5.

[14] Agnes Marx, Bakom järnridån, opublicerad uppsats Malmö högskola, juni 2001, s 2.

[15] Agnes Marx, s 5f.

[16] Agnes Marx, s 9.

[17] Bernard Eric Jensen, "History and the Politics of Identity: Reflections on a Contested and Intricate Issue", i Sirkka Ahonen m fl (red), Historiedidaktikk i Norden 7, Trondheim 1999, s 58.

[18] Harvey J Kaye, "Why Do Ruling Classes Fear History?"and Other Questions, New York 1997, s 134. 